\title{
The study of co-relation of pap smear with colposcopy and histopathology in sexually active woman with unhealthy cervix
}

\author{
Vandana Dhama, Tulika Minz*, Rachna Chaudhary, Shakun Singh
}

Department of Obstetrics and Gynecology, LLRM Medical College, Meerut, Uttar Pradesh, India

Received: 13 May 2021

Accepted: 17 August 2021

\author{
*Correspondence: \\ Dr. Tulika Minz, \\ E-mail: tulika.minz@gmail.com
}

Copyright: (c) the author(s), publisher and licensee Medip Academy. This is an open-access article distributed under the terms of the Creative Commons Attribution Non-Commercial License, which permits unrestricted non-commercial use, distribution, and reproduction in any medium, provided the original work is properly cited.

\begin{abstract}
Background: Unhealthy cervix is a group of cervical lesions, mostly chronic. Cervical cancer is the second most frequent cancer worldwide in women after breast carcinoma cervical cancer is a preventable and curable malignancy if identified and managed early. Primary objective was to study pap smear, colposcopy and histopathology in unhealthy cervix in sexually active woman with secondary objective to screen woman who have abnormal unhealthy, foul smelling cervical discharge.

Methods: The present study was conducted in the department of obstetrics and gynecology L.L.R.M. medical College and associated SVBP hospital, Meerut from June 2019 to May 2020 with sample size of 70. Participant who fit the inclusion criteria were included in the study after taking a written and informed consent. The colposcopy finding was correlated with histopath findings of cervical biopsy that was undertaken.

Results: Co relation of pap smear with colposcopy had sensitivity of $78 \%$ and specificity of $92 \%$ with positive predictive value of $52 \%$ and negative predictive value of $97 \%$, p value less than 0.0001 . The pattern of distribution of histopathological assessment with respect to the pap smear findings was significant statistically $(\mathrm{p}<0.0001)$. The proportion of patients with NILM on pap smear was significantly higher in the VILI negative category compared to the VILI Positive category $(94.12 \%$ vs $77.78 \%, \mathrm{p}=0.0525)$. In the present study, prevalence of CIN of any grade was detected in $8(11.4 \%)$ cases. With CIN 1 in $5(7.14 \%)$ and CIN2 in $2(2.86 \%)$ and CIN3 in $1(1.43 \%)$ case were seen.

Conclusions: Several screening modalities are available of which pap smear is most widely used. colposcopy has been proven very useful to identify and guide the biopsy of dysplastic lesion
\end{abstract}

Keywords: Colposcopy, Pap smear, Specificity, Histopathology, NILM-negative for intraepithelial lesion or malignancy

\section{INTRODUCTION}

Cervical cancer screening ideally finds preinvasive lesions that can be eradicated or finds early-stage cervical cancer that can be treated successfully. Cervical cancer screening was previously limited to cervical cytology. But, during the past decade, HRHPV testing has also become an important screening tool. ${ }^{1}$ Cervical cancer screening ideally begins at the age of 21 years. in average risk woman. Identifying premalignant and benign diseases of the cervix can be challenging. Often, benign cervical disease appears malignant and malignant disease can be hidden from view.
In general, it takes 10 to 20 years for CIN to progress to cancer, allowing a significant time period for detection and treatment. Co-factors associated with persistent HPV infection and progression of disease include smoking, HIV infection, and other types of immunosuppression. Screening for cervical cancer is one of the most prevalent cost effective and successful public health measures for the prevention of cancer because of: Easy accessibility of cervix to inspection and palpation. Propensity of cells to exfoliate from pre-cancerous lesions. ${ }^{2}$ Evidence from pathological studies of existence of histologic changes from mild atypia through pre-malignant lesions to frank malignancy and apparently prolonged natural history. 


\section{METHODS}

Present study was conducted in the department of obstetrics and gynecology, L.L.R.M. medical college and associated with S.V.B.P. hospital, Meerut from June 2019 to May 2020. This prospective clinical study comprises of 70 women who fulfilled the selection criteria attending gynae OPD. The study protocol was approved by the institutional ethical committee.

All subjects were included in the study after obtaining an informed and written consent. Participation in the study was voluntary.

\section{Inclusion criteria}

All sexually active women with unhealthy cervix, postcoital bleeding and intermenstrual bleeding, suspicious cervix, cervical erosion, hypertrophied cervix and abnormal white discharge were included in the study.

\section{Exclusion criteria}

It includes pregnant and women on oral contraceptive pill, post hysterectomy women, diagnosed case of CA cervix.

\section{Steps of examination}

Women as per inclusion and exclusion criteria attending gynae OPD will be considered for the study. A detailed history will be taken, and complete general physical examination will be performed. Women lies down in dorsal lithotomy position; local examination of vulva and perineum is done and the Cusco's self-retaining speculum gently introduced without the use of lubricant. Pap smear is taken if previously not taken. A naked eye examination of the cervix will be done to look for any obvious findings.

\section{Colposcopy}

Colposcope is placed at a distance of one foot from vulva. Preliminary information prior to colposcopy must be documented. Colposcopic findings should be evaluated in conjunction with the history and clinical examination findings. Adequate size bivalve speculum is introduced and opened up halfway to avoid injury to the cervix. Once the cervix is seen, introduce the speculum completely. Now the cervix is examined in low power magnification $(4 \mathrm{x}$ to $8 \mathrm{x})$ and the gross findings on the cervix are noted. ${ }^{3}$

\section{Saline test}

Cervix and vagina are cleaned with normal saline. By keeping the cervix wet, it remains transparent. Dried up cervix becomes translucent. Cervix is now observed for color, surface contour and vascular pattern. The study of vascular pattern is done in detail by inserting green filter under magnification in 10x to $25 x$. Green filter absorbs red color from spectrum and provides a contrast. Blood vessels stand out as black streaks against green background of translucent epithelium. Points to be noted are number of vessels, caliber, tortuosity, vascular pattern and inter capillary distance. Vascular pattern may be typical/atypical in form of mosaic, punctation and abnormal vessels. Inter-capillary distance will increase as the atypia increases.

In vivo study of angio-architecture is possible at this stage and the findings are documented by drawing, photography or histochemistry.

\section{Acetic acid test}

After saline test $5 \%$ acetic acid is either sprayed on cervix and vagina or applied with the help of soaked gauge piece. It takes 45 seconds to one minute for maximum effect. It wears off in 2 to 3 minutes, thus repeated application of acetic acid is required for complete examination. The severity of lesion can be determined by intensity of whiteness, speed of appearance, duration of stay and speed of disappearance. Acetic acid has no effect on original squamous epithelium which is pale and pink. It stains metaplastic and dysplastic epithelium and also columnar epithelium. Individual villi of the columnar epithelium get swollen and assume grape like appearance. When acetowhite lesion is seen on transformation zone its limit has to be delineated. Distal and proximal borders of the transformation zone were identified, and the type of transformation zone was described as type 1, 2 or 3 .

Type 1: Transformation zone entirely on ecto-cervix fully visible, Type 2: Endocervical component, fully visible and type 3: Endocervical component, not fully visible.

\section{Lugol's iodine test}

The $10 \%$ Lugol's Iodine is applied, it stains squamous epithelium as mahogany brown, while endocervical epithelium, immature metaplasia, regenerating and healing squamous epithelium are iodine negative areas. It may partially stain traumatized or inflamed epithelium.

Colposcopy directed biopsies were taken from abnormal areas. They should be carefully excised and fixed in prelabelled bottle of formalin solution. Biopsy should be big enough to include a bit of stroma along with epithelium to exclude invasion

\section{Statistical analysis}

The association between explanatory variables and categorical outcome was assessed by cross tabulation and comparison of percentages value less than 0.05 was considered statistically significant. The data was analyzed by excel and SPSS 26 version 64-bit software. Continuous data like age of subjects was presented as mean \pm SD. Continuous variables were compared using the chi square/Fischer exact test. Diagnostic test was done in terms of sensitivity, specificity, positive predictive value (PPV) and negative predictive value (NPV). 


\section{RESULTS}

The study was conducted on 70 female patients who underwent colposcopy and PAP smear assessment.

The average age of patients was $41.43 \pm 9.96$ years with most of the patients belonging to age group of 20-40 years. The average age at marriage was 22.12 years with a median age of 22 years with most of the patients getting married between $20-25$ years.

The average parity was 3.18 with a median parity of 3 . Most of the patients in the study population belonged to Hindu/Muslim middle or lower class from urban areas.

Most of the patients in the study were not using any amongst the patients who used contraception, barrier method was most common followed by tubal ligation.

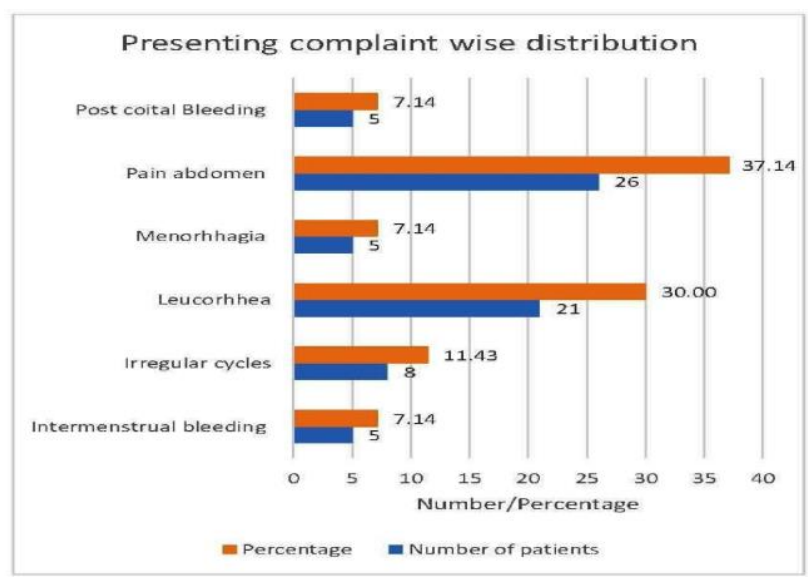

Figure 1: Presenting complaint wise distribution of the study population.

The most common presenting complaint in the study population was pain abdomen $(26,37.14 \%)$ followed by foul smelling discharge $(21,30 \%)$. The 5 cases $(7.14 \%)$ each of intermenstrual bleeding, menorrhagia and post coital bleeding.

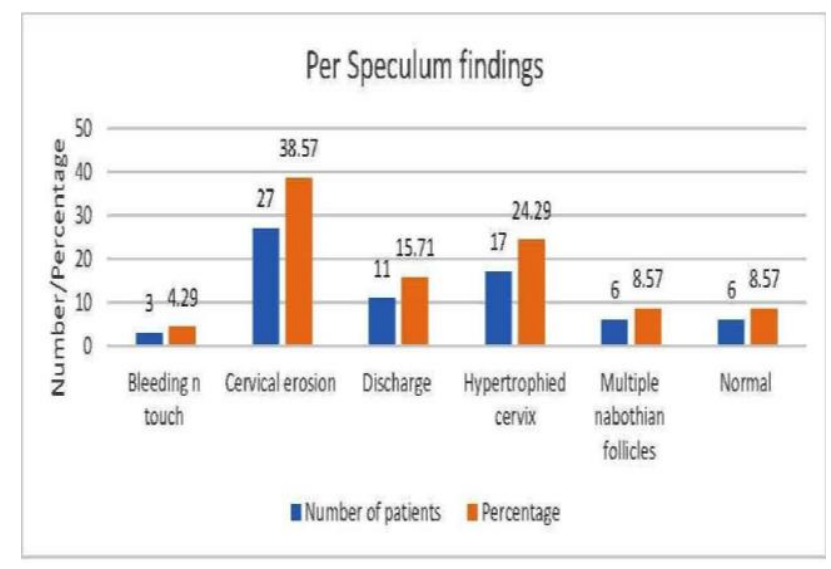

Figure 2: Per speculum findings in the study population.
The most common finding on per speculum examination was cervical erosion $(27,38.57 \%)$ followed by hypertrophied cervix $(17,24.29 \%)$. Only 6 cases $(8.57 \%)$ had a normal per speculum examination. Multiple Nabothian follicles were seen in 6 patients $(8.57 \%)$.



Figure 3: Indications for colposcopy in the study population.

4 indications for colposcopy were seen in the study population. The most common indication for colposcopy was unhealthy cervix seen in 35 patients $(50.00 \%)$ followed by persistent discharge seen in 17 patients $(24.29 \%)$.

The visual inspection using acetic acid was positive in 53 patients $(75.71 \%)$. Thirty-six patients (51.43\%) were positive on visual inspection based on Lugol's iodine. Most common finding on the histopathological assessment was chronic cervicitis $(57,81.43 \%)$. The $5(7.14 \%)$ cases of CIN-1, 2 (2.86\%) cases of CIN-2 and one case (1.43\%) each of CIN-3 and necrotizing tissue were seen in study.

\section{PAP Smear findings and histopathological status}

A comparison of PAP smear findings with the histopathological assessment was done. Most of the patients with NILM on PAP smear had chronic cervicitis (53 out of 60) on histopathology.

The 3 cases with ASCUS on pap smear had chronic cervicitis on histopathology. The 2 cases with ASCUS on pap smear had CIN-1 on histopathology. The 1 case with HSIL on pap smear had CIN-3 on histopathology, 1 case with LSIL on pap smear had CIN-1 on histopathology, 1 case with NILM on pap smear had presence of necrotizing tissue on histopathology and 4 cases with NILM on pap smear had normal histopathology report.

\section{Correlation of pap smear with colposcopy}

The regular screening of population by pap smear is a costeffective method for early detection of premalignant and malignant cervical lesions. Correlation of cervical cytology with cervical biopsies has been a common component of continuous. 
Table 1: P smear findings-based distribution in the study population.

\begin{tabular}{|lll|}
\hline $\begin{array}{l}\text { PAP Smear finding } \\
\text { based distribution }\end{array}$ & $\begin{array}{l}\text { No. of } \\
\text { patients }\end{array}$ & $\begin{array}{l}\text { Percent } \\
(\%)\end{array}$ \\
\hline NILM & 60 & 85.71 \\
\hline ASCUS & 5 & 7.14 \\
\hline LSIL & 2 & 2.86 \\
\hline HSIL & 1 & 1.43 \\
\hline $\begin{array}{l}\text { Persistent } \\
\text { inflammatory changes }\end{array}$ & 1 & 1.43 \\
\hline Unsatisfactory & 1 & 1.43 \\
\hline Grand Total & 70 & 100 \\
\hline
\end{tabular}

Table 2: Histopathological assessment of the study population.

\begin{tabular}{|lll|}
\hline $\begin{array}{l}\text { Histopathological } \\
\text { distribution }\end{array}$ & No. of patients & $\begin{array}{l}\text { Percent } \\
(\%)\end{array}$ \\
\hline Chronic cervicitis & 57 & 81.43 \\
\hline CIN-1 & 5 & 7.14 \\
\hline CIN-2 & 2 & 2.86 \\
\hline CIN-3 & 1 & 1.43 \\
\hline $\begin{array}{l}\text { Necrotising } \\
\text { tissue }\end{array}$ & 1 & 1.43 \\
\hline Normal & 4 & 5.71 \\
\hline Grand total & 70 & 100 \\
\hline
\end{tabular}

Table 3: Pap smear finding and VIA based assessment.

\begin{tabular}{|c|c|c|c|c|c|}
\hline $\begin{array}{l}\text { PAP smear finding } \\
\text { based distribution }\end{array}$ & $\begin{array}{l}\text { VIA } \\
\text { negative (No.) }\end{array}$ & $\begin{array}{l}\text { VIA } \\
\text { negative }(\%)\end{array}$ & $\begin{array}{l}\text { VIA positive } \\
\text { (No.) }\end{array}$ & $\begin{array}{l}\text { VIA positive } \\
(\%)\end{array}$ & P value \\
\hline ASCUS & 0 & 0.00 & 5 & 9.43 & 0.1921 \\
\hline HSIL & 0 & 0.00 & 1 & 1.89 & 0.5708 \\
\hline LSIL & 0 & 0.00 & 2 & 3.77 & 0.4200 \\
\hline NILM & 16 & 94.12 & 44 & 83.02 & 0.2585 \\
\hline $\begin{array}{l}\text { Persistent inflammatory } \\
\text { changes }\end{array}$ & 0 & 0.00 & 1 & 1.89 & 0.5708 \\
\hline Unsatisfactory & 1 & 5.88 & 0 & 0.00 & 0.0775 \\
\hline Grand total & 17 & 100 & 53 & 100 & \\
\hline
\end{tabular}

Table 4: PAP smear finding and VILI based assessment.

\begin{tabular}{|llllll|}
\hline $\begin{array}{l}\text { PAP smear finding } \\
\text { based distribution }\end{array}$ & $\begin{array}{l}\text { VILI } \\
\text { negative (No.) }\end{array}$ & $\begin{array}{l}\text { VILI } \\
\text { negative }\end{array}$ & $\begin{array}{l}\text { VIA positive } \\
(\text { No.) }\end{array}$ & $\begin{array}{l}\text { VILI positive } \\
(\%)\end{array}$ & \begin{tabular}{l} 
P value \\
\hline ASCUS
\end{tabular} \\
\hline HSIL & 0 & 5.88 & 3 & 8.33 & 0.6928 \\
\hline LSIL & 0 & 0.00 & 1 & 2.78 & 0.3309 \\
\hline NILM & 32 & 0.00 & 2 & 5.56 & 0.1661 \\
\hline $\begin{array}{l}\text { Persistent inflammatory } \\
\text { changes }\end{array}$ & 0 & 94.12 & 28 & 77.78 & 0.0525 \\
\hline Unsatisfactory & 0 & 0.00 & 1 & 2.78 & 0.3309 \\
\hline Grand total & 34 & 0.00 & 1 & 2.78 & 0.3309 \\
\hline
\end{tabular}

\section{DISCUSSION}

Regarding age distribution, high incidence of CIN was noted in age range of 20-40 years, with the mean of 41.43 years of age. Maximum women belonged to age group 2040 years $(52.86 \%)$ followed by $41-60$ years $(45.71 \%)$. Amongst rural/urban showed slight urban preponderance $(52.86 \% \mathrm{v} / \mathrm{s} 47.14 \%)$. Most women had a parity between2 to $4(61,87.14 \%)$ followed by 5 or more $(7.10 \%)$.

\section{PAP (cytology), colposcopy and histopathology}

Literature is replete with data pertaining to the sensitivity of pap smear and colposcopy ranging from $27 \%$ to $50 \%$ vs $44 \%$ to $89 \%$ respectively. Specificity of pap smear and colposcopy ranging from $19.5 \%$ to $88.7 \%$ vs $52-93.4 \%$ respectively. Data suggest that with colposcopy as a screening tool, the rate of false negative cytology could be significantly reduced.
Ashmita et al in her study showed, pap smear had better specificity $(83.3 \% \mathrm{v} / \mathrm{s} 72.3 \%)$ compared to colposcopy and colposcopy had a better sensitivity $(90.24 \% \mathrm{v} / \mathrm{s} 19.5 \%)$ compared to pap smear. Colposcopy enhances cervical screening particularly in women with otherwise negative smears. ${ }^{4}$ Correlation between cytology and HPE is poor as far as mild dysplasia were concerned. But the correlation becomes surprisingly good for moderate and severe dysplastic lesions. This indicates the usefulness of colposcopy in diagnosing lesions missed by PAP smear as was seen in a meta-analysis is by Olaniyan et al. ${ }^{5}$ Spectrum of findings on pap smear varied from low-risk lesions like Persistent inflammatory changes $(1,1.43 \%)$ and LSIL (2, $2.86 \%$ ) to high-risk lesions like HSIL $(1,1.43 \%)$.

\section{CONCLUSION}

Cervical carcinoma still constitutes a great clinical and social problem despite splendid diagnostic methods that 
we currently have at our disposal. Invasive cervical cancer is preceded by preinvasive disease in most women. Several screening modalities are available of which pap smear is most widely used. Colposcopy has been proven very useful to identify and guide the biopsy of dysplastic lesion. Data suggest that with colposcopy as a screening tool, the rate of false negative cytology could be significantly reduced. Colposcopy enhances cervical screening particularly in women in otherwise negative smears.

On comparing the PAP smear and histology and colposcopic findings, it was found that PAP smear, as a diagnostic tool for cervical screening had good sensitivity and specificity, with variable positive predictive value and diagnostic accuracy. Colposcopy has been proven very useful to identify and guide the biopsy of dysplastic lesion. The sensitivity of colposcopy is high hence in high-risk population or in remote area where woman do not turn for required screening test, colposcopy can be used primarily as the screening tool.

Funding: No funding sources Conflict of interest: None declared

Ethical approval: The study was approved by the Institutional Ethics Committee

\section{REFERENCES}

1. Crosbie EJ, Einstein MH, Franceschi S, Kitchener HC. Human papillomavirus and cervical cancer. Lancet. 2013;382:889-99.

2. Richart RM. Natural history of cervical intraepithelial neoplasia. Clin Obstet Gynecol. 1968;10;748.

3. Bray F, Ferlay J, Soerjomataram I, Siegel RL, Torre LA, Jemal CA. Up To DATE, Global cancer statistics 2018: GLOBOCAN estimates of incidence and mortality worldwide for 36 cancers in 185 countries. Cancer J Clin. 2018;68(6):394.

4. Basu P, Mittal S, Bhaumik S, Mandal SS, Samaddar A, Ray C et al. Prevalence of high-risk humanpapilloma virus and cervical intraepithelial neoplasias in a previously unscreened population-a pooled analysis from three studies. 2013;132(7):1693-9.

5. Ranga, Rai R, Kumari S, Mathur A, Kriplani S, Alka MD et al. Comparison of the Strength of Association of Reid Colposcopic Index and Swede Score with cervical histology. J Lower Genital Tract Disease. 2017;21(1):55-8.

Cite this article as: Dhama V, Minz T, Chaudhary $\mathrm{R}$, Singh S. The study of co-relation of pap smear with colposcopy and histopathology in sexually active woman with unhealthy cervix. Int J Reprod Contracept Obstet Gynecol 2021;10:3366-70. 